\title{
A Randomized Controlled Study of Efficacy and Safety Profile of Levosulpiride and Itopride in Functional Dyspepsia
}

\author{
Ganesh Narain Saxena ${ }^{1}$, Saumya Mathur ${ }^{2}$
}

\begin{abstract}
Introduction: Dyspepsia is a clinical problem of considerable magnitude for the healthcare system due to the high prevalence and chronic and recurrent nature of symptoms. Earlier dyspepsia was referred to as a heterogeneous group of symptoms in the upper abdomen and retrosternal which are related to ingestion of meals and include heartburn, regurgitation, epigastric pain, epigastric burning, postprandial fullness/distension, early satiety, bloating, belching, anorexia, nausea, and vomiting. This has prompted the search for newer agents with equal efficacy but lower side effect potential such as levosulpiride and itopride.

Aim and objectives: To evaluate and compare the efficacy of the newer drugs like levosulpiride and itopride in functional dyspepsia.

Observations and results: The most common presenting symptoms in the present study were epigastric fullness (81\%), upper abdominal pain $(55 \%)$, early satiety (52\%), and epigastric burning (45\%). Less common symptoms were bloating ( $27 \%)$, belching $(11 \%)$, heartburn (10\%), and nausea (8\%).

Conclusion: Drugs, itopride and levosulpiride, were equally effective in ameliorating different symptoms of functional dyspepsia at the end of 4 weeks of treatment. There was a significant reduction in mean global symptom score (GSS) and mean duration score and mean score of severity in follow-up visits at the 2 nd and 4 th week from the day of presentation ( $p$ value $<0.05$ ).

Keywords: Dyspepsia, Itopride, Levosulpiride, Relief.

Journal of Mahatma Gandhi University of Medical Sciences \& Technology (2020): 10.5005/jp-journals-10057-0131
\end{abstract}

\section{INTRODUCTION}

Dyspepsia is a clinical problem of considerable magnitude for the health care system due to the high prevalence and chronic and recurrent nature of symptoms. ${ }^{1}$

Epidemiological surveys suggest that dyspeptic symptoms have been reported to affect $10-45 \%$ of the general population globally. ${ }^{2}$

Earlier dyspepsia was referred to as a heterogeneous group of symptoms in the upper abdomen and retrosternal which are related to ingestion of meals and include heartburn, regurgitation, epigastric pain, epigastric burning, postprandial fullness/distension, early satiety, bloating, belching, anorexia, nausea, and vomiting. ${ }^{3}$

About $25 \%$ of cases having symptoms of dyspepsia do have an underlying organic lesion in the upper gastroduodenal area, gallbladder, or intestine, and are termed as organic dyspepsia. However, about $75 \%$ of cases having dyspeptic symptoms do not show any underlying organic lesion and are grouped as functional dyspepsia. ${ }^{4,5}$

It was also suggested that symptoms be pooled into four subgroups to reflect their most likely underlying pathophysiology, thereby guide clinicians in their choice of therapy. The subgroups were labeled as reflux-like, ulcer-like, dysmotility-like, and unspecified (non-specified) dyspepsia.."

During the years, consensus committees like ROME II (1999), ROME III (2006), and ROME IV (2016) defined dyspepsia as upper abdominal pain and discomfort centered in the upper abdomen and discomfort includes all Gl symptoms viz. distension, bloating, early satiety, nausea, and burning. It laid down those symptoms should be sufficient to be labeled as bothersome and are severe
1,2Department of General Medicine, Mahatma Gandhi Medical College and Hospital, Jaipur, Rajasthan, India

Corresponding Author: Ganesh Narain Saxena, Department of General Medicine, Mahatma Gandhi Medical College and Hospital, Jaipur, Rajasthan, India, e-mail: gnsaxena@gmail.com

How to cite this article: Saxena GN, Mathur S. A Randomized Controlled Study of Efficacy and Safety Profile of Levosulpiride and Itopride in Functional Dyspepsia. J Mahatma Gandhi Univ Med Sci Tech 2020;5(2):50-56.

Source of support: Nil

Conflict of interest: None

enough to impact normal routine activity. ROME IV also suggests that symptoms of postprandial distress syndrome (PDS) and EPS may coexist. There may be overlapping of symptoms like bloating, belching, heartburn, and pain relief with defecation. ${ }^{7}$

Two categories have been defined:

- Postprandial distress syndrome (PDS) includes patients having postprandial fullness/distension and early satiety several times per week for the last 3 months.

- Epigastric pain syndrome (EPS) includes epigastric pain and burning not relieved by defecation, not generalized nor of the chest or biliary origin.

- Genetic predisposition of patients of functional dyspepsia is thought to be due to prevalence of same in first degree relatives and documentation of polymorphism of G-protein beta polypeptide. ${ }^{8,9}$

(0) The Author(s). 2020 Open Access This article is distributed under the terms of the Creative Commons Attribution 4.0 International License (https:// creativecommons.org/licenses/by-nc/4.0/), which permits unrestricted use, distribution, and non-commercial reproduction in any medium, provided you give appropriate credit to the original author(s) and the source, provide a link to the Creative Commons license, and indicate if changes were made. The Creative Commons Public Domain Dedication waiver (http://creativecommons.org/publicdomain/zero/1.0/) applies to the data made available in this article, unless otherwise stated. 
The use of prokinetic drugs and antisecretory drugs are the common option for the treatment of functional dyspepsia. Prokinetic drugs like metoclopramide, cisapride, and domperidone enhance gastric emptying, prevent retention and reflux of acid or food, and relieve symptoms of dyspepsia. However, metoclopramide causes dystonic reactions and drowsiness, while domperidone has been reported to cause galactorrhea and gynecomastia. ${ }^{10}$ Cisapride has the potential to prolong the QT interval in the electrocardiogram (ECG), and rare but serious cardiac arrhythmias have been reported. ${ }^{11,12}$

This has prompted the search for newer agents with equal efficacy but lower side effect potential such as, levosulpiride: levosulpiride is a benzamide derivative, also has a dual-mode of action, D2 receptor antagonist, and 5HT4 (serotonin) agonist. It was given in doses of $25 \mathrm{mg}$ three times a day orally to patients for 4 weeks in the present study. Levosulpiride is found to accelerate gastric emptying and improve gastrointestinal symptoms in patients with functional dyspepsia ${ }^{13,14}$ and diabetic gastroparesis. ${ }^{15}$

Itopride: Itopride is a veratamide hydrochloride derivative. It has a dual-mode of action as a D2 receptor antagonist and has anticholinesterase activity. It was given in doses of $50 \mathrm{mg}$ three times a day before meals for 4 weeks in patients with functional dyspepsia. The drug is well-tolerated and has minor adverse effects like abdominal pain, diarrhea, and headache. It does not cross the blood-brain barrier so does not have central nervous system (CNS) effects like extrapyramidal symptoms or hyperprolactinoma. It does not affect $5 \mathrm{HT} 4$ receptors on the heart; hence, no cardiac side effect of the prolonged QT interval is seen. ${ }^{16}$

Hence, the study was taken up with the aim, to evaluate and compare the efficacy of the newer drugs like levosulpiride and itopride in functional dyspepsia. To assess the number of patients experiencing side effects on levosulpiride and in itopride. To assess the recurrence of symptoms in functional dyspepsia after 1 month of stoppage of the treatment.

\section{Materials and Methods}

A randomized comparative study was done in the Department of Medicine, Mahatma Gandhi Hospital, Sitapura, Jaipur (Rajasthan) from September 2016 to September 2017. Due approval of the Institutional ethics committee of MGH Medical College was taken before commencing the study also the informed consent was taken from all patients. The study was conducted on 100 patients with functional dyspepsia coming to medicine and gastroenterology OPD. The patients included were fulfilling the following inclusion criteria of age ranging from 15-70 years, of either sex, and were willing to participate in the study. Patients having postprandial symptoms of dyspepsia for at least 3 months like upper abdominal pain, burning, fullness/distension early satiety, bloating, belching, nausea, and heartburn were included in the study. The patients included were having a normal upper gastrointestinal endoscopy and normal upper abdominal ultrasound findings.

The patients who were excluded had some upper gastrointestinal endoscopic findings in form of ulcers, erosions, etc.
Pregnant and lactating women, patients with any neuropsychiatric manifestation. Patients already treated with drugs affecting gastrointestinal motility. After informed consent, detailed history, and physical examination, relevant baseline investigations were done. The 100 patients were randomly divided into group I and group II. Randomization was done by computer-generated random numbers.

Group I patients (50) were given itopride $50 \mathrm{mg}$ thrice a day before meals for a period of 4 weeks. While group II patients (50) were given levosulpiride $25 \mathrm{mg}$ thrice a day before meals for a period of 4 weeks.

The follow-up was done on day 15 and day 30 to assess response to treatment. The treatment was then stopped for a period of 4 weeks in both group I and group II patients.

Another follow-up was scheduled on day 60 to assess the recurrence rate of the symptoms.

To assess the patients at each visit, the following scoring systems ${ }^{17}$ were followed:

Global symptom score (GSS)—depending on the number of symptoms, each complaint of patient per visit was given one score.

\begin{tabular}{ll}
\hline & Score \\
\hline Upper abdominal (epigastric) pain & 1 \\
Upper abdominal (epigastric) & 1 \\
burning & \\
Postprandial distension & 1 \\
Early satiety & 1 \\
Bloating & 1 \\
Belching & 1 \\
Nausea & 1 \\
Heartburn & 1 \\
\hline
\end{tabular}

Duration dependent (4-point score)

\begin{tabular}{ll}
\hline Score & $\begin{array}{l}\text { No. of days symptoms persist per } \\
\text { week }\end{array}$ \\
\hline 1 & $1-2$ days \\
2 & $3-4$ days \\
3 & 5 days \\
4 & All days per week \\
\hline
\end{tabular}

Severity dependent (5-point global score)

\begin{tabular}{lll}
\hline Score & Severity & $\begin{array}{l}\text { Response to treat- } \\
\text { ment }\end{array}$ \\
\hline 1 & Very mild & Symptom-free \\
2 & Mild occur & Markedly improved \\
3 & Moderate & $\begin{array}{l}\text { Moderately im- } \\
\text { proved }\end{array}$ \\
4 & Severe & Not changed \\
5 & Very severe & Deteriorated \\
\hline
\end{tabular}


A Randomized Controlled Study of Efficacy and Safety Profile of Levosulpiride and Itopride in Functional Dyspepsia

The adverse effects which were to be looked upon on follow-up visits were as:

\begin{tabular}{|c|c|c|c|c|c|}
\hline \multirow{2}{*}{$\frac{\text { Adverse events }}{\text { GIT }}$} & \multicolumn{5}{|c|}{ Name of symptoms } \\
\hline & Abdominal cramps & Loose stool & Constipation & Others & \\
\hline CNS & Sleeplessness & Vertigo & Fatigue & Headache & Others \\
\hline Hormonal & Weight gain & Galactorrhea & Breast tenderness & Hoarseness & Others \\
\hline CVS & ECG changes & Arrhythmias & Palpitation & Others & \\
\hline Others & Rashes & Dry mouth & Hypersalivation & & \\
\hline
\end{tabular}

Table 1: Effect of therapy on upper abdominal pain

\begin{tabular}{|c|c|c|c|c|c|c|}
\hline \multirow[b]{2}{*}{ Visit (in weeks) } & \multicolumn{2}{|c|}{ Group I } & \multicolumn{2}{|c|}{ Group II } & & \multirow[b]{2}{*}{$p$ value } \\
\hline & No. & $\%$ & No. & $\%$ & & \\
\hline 0 Week & 26 & 52 & 29 & 58 & 0.36 & 0.546 \\
\hline 2 Weeks & 4 & 8 & 1 & 2 & 1.89 & 0.169 \\
\hline 4 Weeks & 1 & 2 & 0 & 0 & NA & NA \\
\hline 8 Weeks & 0 & 0 & 0 & 0 & NA & NA \\
\hline
\end{tabular}

Table 2: Effect of therapy on epigastric burning

\begin{tabular}{|c|c|c|c|c|c|c|}
\hline \multirow[b]{2}{*}{ Visit (in weeks) } & \multicolumn{2}{|c|}{ Group I } & \multicolumn{2}{|c|}{ Group II } & & \multirow[b]{2}{*}{$p$ value } \\
\hline & No. & $\%$ & No. & $\%$ & & \\
\hline 0 Week & 22 & 44 & 23 & 46 & 0.04 & 0.841 \\
\hline 2 Weeks & 4 & 8 & 3 & 6 & 0.15 & 0.695 \\
\hline 4 Weeks & 0 & 0 & 0 & 0 & NA & NA \\
\hline 8 Weeks & 0 & 0 & 3 & 6 & NA & NA \\
\hline
\end{tabular}

Table 3: Effect of therapy on abdominal fullness

\begin{tabular}{|c|c|c|c|c|c|c|}
\hline \multirow[b]{2}{*}{ Visit (in weeks) } & \multicolumn{2}{|c|}{ Group I } & \multicolumn{2}{|c|}{ Group II } & & \multirow[b]{2}{*}{$p$ value } \\
\hline & No. & $\%$ & No. & $\%$ & & \\
\hline 0 Week & 40 & 80 & 41 & 82 & 0.06 & 0.799 \\
\hline 2 Weeks & 13 & 26 & 6 & 12 & 3.18 & 0.074 \\
\hline 4 Weeks & 1 & 2 & 0 & 0 & NA & NA \\
\hline 8 Weeks & 0 & 0 & 5 & 10 & NA & NA \\
\hline
\end{tabular}

Table 4: Effect of therapy on early satiety

\begin{tabular}{|c|c|c|c|c|c|c|}
\hline \multirow[b]{2}{*}{ Visit (in weeks) } & \multicolumn{2}{|c|}{ Group I } & \multicolumn{2}{|c|}{ Group II } & & \multirow[b]{2}{*}{$p$ value } \\
\hline & No. & $\%$ & No. & $\%$ & & \\
\hline o Week & 27 & 54 & 25 & 50 & 0.16 & 0.689 \\
\hline 2 Weeks & 13 & 26 & 6 & 12 & 3.18 & 0.074 \\
\hline 4 Weeks & 2 & 4 & 0 & 0 & NA & NA \\
\hline 8 Weeks & 3 & 6 & 2 & 4 & NA & NA \\
\hline
\end{tabular}

The statistical analysis was done by using mean and standard deviation (SD) of global score and response to treatment score was assessed at day 0 , day 15 , day 30 , and day 60 . Unpaired $t$-test, child X-2, Mann-Whitney, ANOVA was used for statistical analysis. A $p$ value of $<0.05$ was considered statistically significant.

\section{Observation and Results}

In group I, only four patients (8\%) at week 2 and only one patient (2\%) at 4 weeks had pain abdomen, whereas in group II only one patient (2\%) at the 2 nd week and none at 4 weeks had pain in the abdomen. There was an insignificant difference in both groups of patients who were not responding to treatment ( $p$ value 0.169 ) (Table 1).

In group I, only four patients (8\%) at 2 weeks and none patient at 4 weeks had epigastric burning. While in group II, three patients (6\%) at the 2 nd week and none at 4 weeks had epigastric burning.
There was an insignificant difference in both groups of patients who are not responding to treatment ( $p$ value 0.695 ) (Table 2).

In group I, 13 patients (26\%) at 2 weeks and 1 patient (2\%) at 4 weeks were having abdominal fullness. While in group II, six patients (12\%) at the 2 nd week and none at 4 weeks had abdominal fullness. There was an insignificant difference in both groups of patients who were not responding to treatment ( $p$ value 0.074 ) (Table 3 ).

In group I, 13 patients (26\%) at 2 weeks and 2 patients (4\%) at 4 weeks were having persistent early satiety. While in group II, six patients (12\%) at the 2 nd week and none at 4 weeks had persistent early satiety. There was an insignificant difference in both groups of patients who were not responding to treatment ( $p$ value 0.074 ) (Table 4).

In group I, seven patients (14\%) at the 2 nd week and two patients (4\%) at 4 weeks had persistent PP bloating. While in group II, two patients (4\%) at the 2 nd week and none at 4 weeks had persistent PP bloating. There is an insignificant difference in both 
Table 5: Effect of therapy on postprandial bloating

\begin{tabular}{|c|c|c|c|c|c|c|}
\hline \multirow[b]{2}{*}{ Visit (in weeks) } & \multicolumn{2}{|c|}{ Group I } & \multicolumn{2}{|c|}{ Group II } & & \multirow[b]{2}{*}{$p$ value } \\
\hline & No. & $\%$ & No. & $\%$ & & \\
\hline o Week & 14 & 28 & 13 & 26 & 0.05 & 0.822 \\
\hline 2 Weeks & 7 & 14 & 2 & 4 & 3.05 & 0.081 \\
\hline 4 Weeks & 2 & 4 & 0 & 0 & NA & NA \\
\hline 8 Weeks & 1 & 2 & 0 & 0 & NA & NA \\
\hline
\end{tabular}

Table 6: Effect of therapy on postprandial belching

\begin{tabular}{|c|c|c|c|c|c|c|}
\hline \multirow[b]{2}{*}{ Visit (in weeks) } & \multicolumn{2}{|c|}{ Group I } & \multicolumn{2}{|c|}{ Group II } & & \multirow[b]{2}{*}{$p$ value } \\
\hline & No. & $\%$ & No. & $\%$ & & \\
\hline 0 Week & 3 & 6 & 8 & 16 & 2.55 & 0.110 \\
\hline 2 Weeks & 3 & 6 & 3 & 6 & 0.00 & 1.000 \\
\hline 4 Weeks & 0 & 0 & 0 & 0 & $\mathrm{NA}$ & NA \\
\hline 8 Weeks & 0 & 0 & 0 & 0 & NA & NA \\
\hline
\end{tabular}

Table 7: Effect of therapy on heartburn

\begin{tabular}{|c|c|c|c|c|c|c|}
\hline \multirow[b]{2}{*}{ Visit (in weeks) } & \multicolumn{2}{|c|}{ Group I } & \multicolumn{2}{|c|}{ Group II } & & \multirow[b]{2}{*}{$p$ value } \\
\hline & No. & $\%$ & No. & $\%$ & & \\
\hline o Week & 3 & 6 & 7 & 14 & 1.78 & 0.182 \\
\hline 2 Weeks & 1 & 2 & 1 & 2 & 0.00 & 1.000 \\
\hline 4 Weeks & 0 & 0 & 0 & 0 & NA & NA \\
\hline 8 Weeks & 0 & 0 & 0 & 0 & NA & NA \\
\hline
\end{tabular}

Table 8: Effect of therapy on nausea

\begin{tabular}{|c|c|c|c|c|c|c|}
\hline \multirow[b]{2}{*}{ Visit (in weeks) } & \multicolumn{2}{|c|}{ Group I } & \multicolumn{2}{|c|}{ Group II } & & \multirow[b]{2}{*}{$p$ value } \\
\hline & No. & $\%$ & No. & $\%$ & & \\
\hline o Week & 0 & 0 & 4 & 8 & $\mathrm{NA}$ & NA \\
\hline 2 Weeks & 0 & 0 & 1 & 2 & NA & NA \\
\hline 4 Weeks & 0 & 0 & 0 & 0 & NA & NA \\
\hline 8 Weeks & 0 & 0 & 0 & 0 & NA & NA \\
\hline
\end{tabular}

groups of patients who were not responding to treatment ( $p$ value 0.081) (Table 5).

In group I, three patients (6\%) at 2 weeks and none at 4 weeks had persistent belching. While in group II also, three patients (6\%) at the 2nd week and none at 4 weeks had belching. There is an insignificant difference in both groups of patients not responding to treatment ( $p$ value 1.000) (Table 6).

In group I, only one patient at 2nd week and none at 4 weeks had heartburn. While in group II also, one patient had heartburn at the 2 nd week and none had at 4 weeks. There is an insignificant difference in both groups of patients not responding to treatment ( $p$ value 1.000) (Table 7).

In group I, none had nausea at the 2 nd and 4th week, while in group II only one patient (2\%) had nausea at the 2 nd week and none at the 4th week. There is an insignificant difference (Tables 8 and 9).

\section{Discussion}

Functional dyspepsia is a common condition; symptomatic improvement after prokinetic drug therapy may be incomplete and obtained in about $60-80 \%$ of patients. ${ }^{18}$ This study was to evaluate and compare the efficacy of the newer drugs like levosulpiride and itopride in functional dyspepsia.

In this study, a total of 132 patients were enrolled, out of which 100 patients ( 50 in group I and 50 in group II), fulfilled the inclusion and exclusion criteria and were included in the study. The mean age of patients was 38 years and dyspeptic symptoms were less prevalent in extremes of age. This finding is consistent with the study done by Sati ${ }^{19}$ who also found functional dyspepsia common in the age group of 18-60 years, mean age 37-38 years.

In our study, there was a male preponderance, 70 patients were male and 30 patients were female. In contrast to this, a study done by Sati $^{19}$ observed a female preponderance, male:female ratio 1:2 in their study.

The most common presenting symptoms of our study were upper abdominal pain, epigastric burning, abdominal fullness, early satiety, and postprandial bloating while the fewer common symptoms were belching, heartburn, and nausea.

\section{Effect of Therapy on Upper Abdominal Pain}

As seen in Table 1, patients who were having upper abdominal pain at initial presentation ( 0 weeks) were 26 in group I and 29 in group II. 
Table 9: Adverse effects

\begin{tabular}{llllll}
\hline & \multicolumn{3}{c}{ Group I } & & \multicolumn{2}{c}{ Group II } \\
\cline { 2 - 3 } \cline { 5 - 6 } GIT & No. & $\%$ & & No. & $\%$ \\
\hline Add. cramp & 1 & 2 & & 0 & 0 \\
Loose motion & 0 & 0 & & 4 & 8 \\
Constipation & 1 & 2 & 0 & 0
\end{tabular}

\begin{tabular}{llllll} 
Constipation & 1 & 2 & & 0 & 0 \\
\cline { 2 - 3 } \cline { 5 - 6 } CNS & & Group I & & Group II \\
\cline { 2 - 3 } \cline { 5 - 6 } Somnolence & 0 & $\%$ & & No. & $\%$ \\
Vertigo & 0 & 0 & & 0 & 0 \\
Fatigue & 0 & 0 & & 0 & 8 \\
Headache & 0 & 0 & 1 & 0 \\
\hline
\end{tabular}

\begin{tabular}{llllll} 
& \multicolumn{3}{c}{ Group I } & & \multicolumn{2}{c}{ Group II } \\
\cline { 2 - 3 } \cline { 5 - 5 } Hormonal & No. & $\%$ & & No. & $\%$ \\
\hline Wt. gain & 0 & 0 & 1 & 2 \\
Galactorrhea & 0 & 0 & 1 & 2 \\
Breast & 0 & 0 & 0 & 0 \\
tenderness & & & & \\
\hline
\end{tabular}

\begin{tabular}{llllll}
\hline & \multicolumn{3}{c}{ Group I } & & \multicolumn{2}{c}{ Group II } \\
\cline { 2 - 3 } \cline { 5 - 5 } CVS & No. & $\%$ & & No. & $\%$ \\
\hline $\begin{array}{l}\text { Others } \\
\text { (allergic } \\
\text { reactions) }\end{array}$ & 2 & 4 & 0 & 0 \\
\hline
\end{tabular}

In group I, 22 patients (84.6\%) at the 2 nd week and 25 patients (96.1\%) at the 4th week were relieved of their pain abdomen. In group II, 28 patients (96.3\%) at the 2 nd week and all 29 patients $(100 \%)$ at the 4 th week were free of abdominal pain. The response of therapy for upper abdominal pain at the 2nd and 4th week for both groups I and II are similar.

None patients had a recurrence of pain at the 8th week (after 4 weeks of stoppage of treatment). There is no recurrence of abdominal pain after stoppage of treatment in both groups.

\section{Effect of Therapy on Epigastric Burning}

As seen in Table 2, 45 patients were having epigastric burning at initial presentation, 22 in group I and 23 in group II.

In group I, 18 patients (81.1\%) at the 2 nd week and all 22 patients (100\%) at the 4th week were free of epigastric burning. None patients had a recurrence of epigastric burning at the 8th week. In group II, 20 patients (86.9\%) at the 2nd week and all 23 patients (100\%) at the 4th week were free of epigastric burning. Three patients (13\%) had a recurrence of epigastric burning at the 8 th week. The response of therapy for epigastric burning at the 2 nd week ( 81 vs $86 \%$ ) and 4th week (100 vs $100 \%$ ) are almost similar in both groups.

There is some difference in the recurrence in relation to epigastric burning in two groups at the end of the 8th week. Three patients (13\%) in group II had a recurrence of pain at the 8th week and none in group $\mathrm{I}$.

\section{Effect of Therapy on Postprandial Upper Abdominal Fullness}

As per Table 3, in our study, abdominal fullness was a common symptom at initial presentation. Out of the 100, 81 patients had symptoms of abdominal fullness at 0 weeks, 40 in group I and 41 in group II.

In group I, 27 patients (67.5\%) at the 2 nd week and 39 patients $(97.5 \%)$ at the 4 th week were relieved of their abdominal fullness and none patients had a recurrence of abdominal fullness at the 8 th week. In group II, 35 patients (85.36\%) at the 2 nd week, and all 41 patients (100\%) had their abdominal fullness at the 8th week. The response of therapy for upper abdominal fullness at the 2nd week (67.5\% vs $85 \%)$ and 4 th week (97.5\% vs $100 \%)$ in group I and group II, respectively.

None patients in group I and five patients (12.5\%) in group II had a recurrence of abdominal fullness at the 8th week, 4 weeks after stopping the treatment.

\section{Effect of Therapy on Early Satiety}

As per Table 4, 52 patients presented with symptoms of early satiety, 27 in group I and 25 in group II.

In group I, 14 patients $(51.85 \%)$ at the 2 nd week and 25 patients $(92.5 \%)$ at the 4 th week improved and 3 patients (11\%) have a recurrence of early satiety at the 8th week. In group II, 19 patients (73.09\%) at the 2 nd week and all 25 patients at the 4th week had improvement and 2 patients (8\%) had a recurrence of early satiety at the 8th week. Response for the amelioration of early satiety was comparable in both groups I and II after treatment at the 4th week (92\% vs $100 \%)$, respectively.

There was a recurrence of symptoms of early satiety after stoppage of treatment at the 8 th week, three patients (6\%) in group I and two patients in group II.

\section{Effect of Therapy on Postprandial Bloating}

Out of a total of 100 patients, 27 patients were having postprandial bloating at presentation, 14 in group I and 13 in group II (Table 5).

In group I, 7 patients (50\%) at the 2 nd week and 12 patients $(85 \%)$ at the 4 th week were relieved of bloating and 1 patient $(7 \%)$ had a recurrence of bloating at the 8 th week. In group II, 11 patients $(84.6 \%)$ at the 2 nd week and all 13 patients (100\%) at the 4th week were relieved of bloating and none had a recurrence of bloating at the 8th week. The response of therapy to both groups of patients I and II at the 4th week was 85 vs $100 \%$. Only one patient had a recurrence of PP bloating after stoppage of treatment at the 8th week and none had a recurrence in group II.

\section{Effect of Therapy on Belching}

As per Table 6, three patients (6\%) in group I and eight patients $(16 \%)$ in group II were having to belch at presentation.

In group I, no patient ( $0 \%$ ) at the 2 nd week and all patients $(100 \%)$ at the 4 th week were relieved of belching and none had a recurrence of belching at the 8th week. In group II, five patients $(62.5 \%)$ at the 2 nd week and all patients (100\%) at the 4th week were relieved of belching and none had a recurrence of belching at the 8th week.

\section{Effect of Therapy on Heartburn}

As per Table 7, in our study, 10 patients presented with heartburn along with other symptoms, 3 patients (6\%) in group I and 7 patients in group II.

In group I, two patients (66.6\%) at the 2 nd week and all three patients $(100 \%)$ at the 4 th week were relieved of heartburn and none patient had a recurrence of heart at the 8 th week. In group II, six patients (85\%) at the 2 nd week and all seven patients (100\%) at 
the 4th week were relieved of heartburn 4 weeks after stoppage of treatment.

\section{Effect of Therapy on Nausea}

As per Table 8, four patients presented with nausea, none in group I and 4 in group II.

In group II, all four patients (100\%) were relieved of nausea at the 2 nd week and remain relieved at the 4 th and 8 th week. There was no recurrence of nausea 4 weeks after the stoppage of treatment in both groups.

\section{Adverse Effects Noted in the Study}

Table 9 shows in group I (patients taking itopride) only four patients, had adverse effects. Abdominal cramps and constipation in one patient each, two patients had an allergic reaction in the form of itching in whom drugs were stopped. While in group II (patients taking levosulpiride) 13 patients had adverse effects such as loose motion and obsolescence, in 4 patients each. Less common adverse effects noted were headache, weight gain, and galactorrhea.

In our study, extrapyramidal side effects (EPS) have not been reported in any case in both groups. No case of QT prolongation or an episode of arrhythmia has been reported with itopride and levosulpiride.

In a study done by Corrazza $^{20}$ et al., tolerability of levosulpiride was assessed in 840 patients with dyspepsia. The incidence of adverse events was $11 \%$. Drowsiness was the most frequent so sedation as adverse events (2.5\%), which was not seen in our study.

Levosulpiride may elevate prolactin levels $>200 \mathrm{mg} / \mathrm{mL}$ in patients and subsequently cause galactorrhea and menstrual abnormalities in patients, as reported by Kuchay and Mithal in $2017,{ }^{21}$ which is similar to our study where we have observed galactorrhea in few patients.

In our study, we have not encountered any such patients with hemichorea/parkinsonism/or increase prolactin levels with the use of levosulpiride while in contrast hemichorea was reported with the use of levosulpiride, in 2016 by Mathew. ${ }^{22}$

Sati in $2010^{19}$ observed aphthous ulcer and constipation as an adverse effect in few patients taking itopride. Gerald Hotman et al. in $2006^{9}$ observed abdominal pain, diarrhea, nausea, and constipation are the most common adverse effect with the use of itopride.

\section{Recurrence of Symptoms}

After 4 weeks, treatment was stopped and follow-up was done at the 8th week. Four patients had a recurrence of symptoms at the 8 th week in group I. Ten patients had a recurrence of symptoms at the 8 th week in group II. No patients had GSS $>4$ in group IV and group II, respectively.

Most of the findings in our study are comparable with other studies in which levosulpiride consistently showed statistical and clinical superiority over placebo and other prokinetic drugs in reducing the symptoms.

A study done by Arienti et al. ${ }^{23}$ revealed similar efficacy in the patients treated with levosulpiride and domperidone. Two studies (Mansi et al. ${ }^{24}$ and Mangiameli et al. ${ }^{25}$ ) done on symptomatic patients with diabetic gastroparesis showed that levosulpiride was significantly superior to placebo in improving dyspeptic symptoms such as nausea, upper abdominal discomfort, and vomiting.

In another study done by Corrazza and Tonini, ${ }^{20}$ where a total of 1,818 patients were included, 676 were given levosulpiride. The drug was effective in a dose of $25 \mathrm{mg}$ TID oral in improving GI symptoms compared with placebo and other prokinetic drugs. At this dosage, levosulpiride was more effective than a recommended oral dose of domperidone and metoclopramide.

In a study conducted by Mangiameli et al., ${ }^{25}$ there was a significant improvement in abdominal fullness, belching, and other global symptoms in patients who were administered levosulpiride or domperidone regarding postprandial bloating and epigastric pain, an improvement was seen more in the levosulpiride group, while nausea and heartburn improved more in domperidone group.

In another study by Distrutti et al. ${ }^{26}$ done on functional dyspepsia, oral administration of levosulpiride in a dose of $25 \mathrm{mg}$ TID oral for 4 weeks notable ameliorated dyspeptic symptoms and was found to be significantly effective $(p<0.05)$ in reducing nausea, upper abdominal pain, abdominal fullness, and early satiety.

In another study, by Mohanan and Sankaran ${ }^{27}$ of 31 patients, each levosulpiride was significantly better than placebo at 2 and 4 weeks of treatment $(<0.001)$.

Lozana et al. ${ }^{18}$ in a multicenter study in 342 patients showed that with use of levosulpiride in patients of functional dyspepsia decrease in $50 \%$ of GSS at the 2 nd week and $>80 \%$ at the 4 th week. Levosulpiride was effective significantly in reducing symptoms.

Yang et al. in randomized controlled trial ${ }^{28}$ showed that metoclopramide, domperidone, mosapride, trimebutine showed a better effect in patients of functional dyspepsia than itopride and acotiamide.

Hassan et al. ${ }^{29}$ in his original research article compared the efficacy and safety of levosulpiride and itopride in patients with gastroesophageal reflux disease. He observed levosulpiride superior to itopride in terms of early effects and better quality of life in these patients.

Most of the findings in our study are comparable with other studies in which itopride consistently showed statistical and clinical superiority over placebo and other prokinetic drugs in reducing the syptoms.

Sati ${ }^{19}$ found itopride significantly better in lowering symptom scores over placebo 9.3 vs 14.4 ( $p$ value 0.0004 ) in patients having predominantly bloating and fullness.

One large series by Holtmann et al. ${ }^{30}$ observed that itopride shows significant improvement in patients with dyspepsia.

Huang et al. ${ }^{31}$ in meta-analysis in the world journal of gastroenterology concluded that itopride is effective in postprandial fullness and early satiety as shown in global patient assessment. Talley et al. ${ }^{32}$ did not find any difference in response rate between itopride and placebo. Kasinenko and Denisovnl found itopride effective and well-tolerated in Russian patients. Dite and Rydio reported itopride is a good drug with dual effects in the treatment of dysmotility including functional dyspepsia.

Kamiya et al. ${ }^{17}$ found itopride effective in patients of functional dyspepsia when compared with rabeprazole.

\section{Summary and Conclusion}

It is the most frequently presented complaint in day-to-day medical practice based on the diagnostic criteria for functional dyspepsia, Dyspepsia symptoms include epigastric burning, postprandial fullness, early satiety, and bloating, belching, nausea, and heartburn. Apart from the use of antisecretory drugs, various prokinetics have been used frequently for the management of functional dyspepsia and other motility disorders including gastroparesis, emesis, and IBS. This study demonstrates the efficacy and tolerability of two prokinetics, itopride and levosulpiride in patients of functional dyspepsia. 
In this study, the most common presenting symptoms in the present study were epigastric fullness (81\%), upper abdominal pain (55\%), early satiety (52\%), and epigastric burning (45\%). Less common symptoms were bloating $(27 \%)$, belching $(11 \%)$, heartburn (10\%), and nausea (8\%).

Both drugs, itopride and levosulpiride, were equally effective in ameliorating different symptoms of functional dyspepsia at the end of 4 weeks of treatment. There was a significant reduction in mean GSS and mean duration score and mean score of severity in follow-up visits at the 2nd and 4th week from the day of presentation ( $p$ value $<0.05$ )

Only four patients (8\%) taking itopride suffered adverse effects such as abdominal cramp and constipation were seen in one patient each and in two patients itopride had to be stopped because of allergic rash. Thirteen patients (10\%) taking levosulpiride showed adverse reactions such as loose motions (4), somnolence (4), two had vertigo and one each presented with headache, weight gain, and galactorrhea. In the present study, none of the patients had EPS (extrapyramidal side effects) nor had an episode of arrhythmia or prolongation of QT interval.

During the follow-up at the 8th week, it was observed that 4 patients had a recurrence of symptoms in group I and 10 in group II. It is thus concluded that both itopride and levosulpiride are an effective alternative to each other in the treatment of patients with functional dyspepsia for 4 weeks of duration. Both itopride and levosulpiride are well-tolerated.

\section{References}

1. Penston JG, Pounder RE. A survey of dyspepsia in Great Britain. Aliment Pharmacol Ther 1996;10(1):83-89. DOI: 10.1111/j.13652036.1996.tb00180.x

2. Talley NJ, Zinsmeister AR, Schleck CD, et al. Dyspepsia and dyspepsia subgroups: a population-based study. Gastroenterology 1992;102(4):1259-1268. DOI: 10.1016/0016-5085(92)90764-P.

3. Boekema PJ, van Isselt EF, Bots ML, et al. Functional bowel symptoms in a general Dutch population and associations with common stimulants. Neth J Med 2001;59(1):23-30. DOI: 10.1016/S03002977(01)00128-0.

4. Moayyedi P, Talley NJ, Fennerty MB, et al. Can the clinical history distinguish between organic and functional dyspepsia? JAMA 2006;295(13):1566-1576. DOI: 10.1001/jama.295.13.1566.

5. Ford AC, Marwaha A, Lim A, et al. What is the prevalence of clinically significant endoscopic findings in subjects with dyspepsia? systematic review and meta-analysis. Clin Gastroenterol Hepatol 2010;8(10):830-837. DOI: 10.1016/j.cgh.2010.05.031.

6. Colin-Jones DG. Management of dyspepsia: report of a working party. Lancet 1998. 567-569.

7. Vanheel H, Carbone F, Valvekens L, et al. Dyspepsia subgroups according to the ROME III criteria. Am J Gastroenterol 2007;112(1):132140. DOI: 10.1038/ajg.2016.499.

8. Locke GR, Zinsmeister AR, Talley NJ, et al. Familial association in adults with functional gastrointestinal disorders. Mayo Clin Proc 2000;75(9)):907-912. DOI: 10.4065/75.9.907.

9. Holtmann G, Siffert W, Haag S, et al. G-protein $\beta 3$ submit 825 CC genotype is associated with unexplained (functional) dyspepsia. Gastroenterology 2004;126(4):971-979. DOI: 10.1053/j. gastro.2004.01.006.

10. Pasricha PJ, Chapter No.38. Prokinetic agents, antiemetics, and agents used in irritable bowel syndrome. Goodman\& Gilman's The pharmacological basis of therapeutics, Hardman JG, Limbird LE, Gilman AG.

11. Olsson S, Edwards IR. Tachycardia during cisapride treatment. BMJ 1992;305(6856):748-749. DOI: 10.1136/bmj.305.6856.748-a.

12. Wysowski DK, Corken A, Gallo-Torres $\mathrm{H}$, et al. Post marketing reports of QT prolongation and ventricular arrhythmia in association with cisapride and food and drug administration regulatory actions. The American journal of gastroenterology 2001;96(6):1698-1703. DOI: 10.1111/j.1572-0241.2001.03927.x.

13. Arienti V, Corazza GR, Sorge M, et al. The effects of levosulpiride of gastric and gall-bladder emptying in functional dyspepsia. Aliment Pharmacol Ther 1994;8(6):631-638. DOI: 10.1111/j.1365-2036.1994. tb00341.x.

14. Mansi C, Borro P, Giacomini M, etal.Comparative effects of levosulpiride and cisapride on gastric emptying and symptoms in patients with functional dyspepsia and gastroparesis. Aliment Pharmacol Ther 2000;14(5):561-569. DOI: 10.1046/j.1365-2036.2000.00742.x.

15. Iwanaga $Y$, Kimura $T$, Miyashita $N$, et al. Characterization of acetylcholinesterase-inhibition by itopride. Japan J Pharmacol 1994;66(3):317-322. DOI: 10.1254/jjp.66.317.

16. Banka NH. Role of prokinetics in dyspepsia. Gastroenterol Today 2003;7(1):1-4.

17. Kamiya $\mathrm{T}$, Shikano $\mathrm{M}$, Kubota $\mathrm{E}$, et al. A multicenter randomized trial comparing rabeprazole and itopride in patients with functional dyspepsia in Japan: the NOGOYA study. J Clin Biochem Nutr 2017;60(2):130-135. DOI: 10.3164/jcbn.16-106.

18. Lozana R, Concha MP, Montealeague A, et al. Effectiveness and safety of levosulpiride in the treatment of dysmotility like functional dyspepsia. Ther Clin Risk Manag 2007;3(1):149. DOI: 10.2147/ tcrm.2007.3.1.149.

19. Sati S. J Digest Endos 2010;1(4):171-175.

20. Corrazza GR, Tonini M. Levosulpiride for dyspepsia and emesis. Clin Drug Investig 2000;19(2):151-162. DOI: 10.2165/00044011-20001902000008.

21. Kuchay MS, Mithal A. Levosulpiride and serum prolactin levels. Indian J Endocrinol Metab 2017;21(2):355. DOI: 10.4103/ijem.IJEM_555_16.

22. Mathew T, Nadimpally U, Prabhu A, et al. Drug-induced parkinsonism on the rise: beware of levosulpiride and its combinations with proton pump inhibitors. Neurol India 2017;65(1):173. DOI: 10.4103/00283886.198175.

23. Arienti V, Ferrentino M, Micaletti E. Studio sull'efficaciadella levosulpiride nella dyspepsia e sulladinamicamotoriadellacolecisti. Provacontrollata verso Domperidone Minerva Dietol Gastroenterol 1987:33:1-5.

24. Mansi C, Savarino V, Vigneri S, et al. Gastrokinetic effects of levosulpiride in dyspeptic patients with diabetic gastroparesis. American Journal Of Gastroenterology 1995;90(11):1989-1993.

25. Mangiameli A, Brogna A, Catanzaro R, et al. Levosulpiride versus domperidone in the treatment of functional dyspepsia. La clinicaterapeutica 1994;144(2):107-114.

26. Distrutti E, Fiorucci S, Hauer SK, et al. Effect of acute and chronic levosulpiride administration on gastric tone and perception in functional dyspepsia. Aliment Pharmacol Ther 2002;16(3):613-622. DOI: 10.1046/j.1365-2036.2002.01180.x.

27. Mohanan LK, Sankaran BC. Randomized double blind placebocontrolled trial to assess the efficacy and tolerability of levosulpiride in dysmotility type of functional dyspepsia. J Evolut Med Dental Sciences 2016;5(30):1506-1510. DOI: 10.14260/jemds/2016/355.

28. Yang YJ, Bang CS, Baik GH, et al. Prokinetics for the treatment of functional dyspepsia: Bayesian network meta-analysis. BMC Gastroenterol 2017;17(1):83. DOI: 10.1186/s12876-017-0639-0.

29. Hassan SI, Hassan SM. Comparison of safety and efficacy of levosulpiride and itopride in treatment of gastroesophageal reflux disease. J Evid Med Healthcare 2017;4(6):292-297. DOI: 10.18410/ jebmh/2017/55.

30. Holtmann G, Talley NJ, Liebregts T, et al. A placebo-controlled trial of itopride in functional dyspepsia. N Eng J Med 2006;354(8):832-840. DOI: 10.1056/NEJMoa052639.

31. Huang $X, L v B, Z$ hang $S$, et al. Itopride therapy for functional dyspepsia: a meta-analysis. World J Gastroenterol 2012;18(48):7371. DOI: 10.3748/ wjg.v18.i48.7371.

32. Talley NJ, Tack J, Ptak T, et al. Itopride in functional dyspepsia: results of two phase III multicenter, randomized, double-blind, placebocontrolled trials. Gut 2008;57(6):740-746. DOI: 10.1136/gut.2007. 132449. 